\title{
TEOR DE TANINOS EM TRÊS ESPÉCIES MEDICINAIS ARBÓREAS SIMPÁTRICAS DA CAATINGA ${ }^{1}$
}

Julio Marcelino Monteiro², Ernani Machado de Freitas Lins Neto ${ }^{3}$, Elba Lúcia Cavalcanti de Amorim ${ }^{4}$, Ruth R. Strattmann ${ }^{4}$, Elcida Lima Araújo ${ }^{5}$ e Ulysses Paulino de Albuquerque ${ }^{5 *}$

\begin{abstract}
RESUMO - O teor de taninos em três espécies medicinais do semi-árido do Nordeste do Brasil foi determinado. A partir de amostras das cascas do caule e folhas de 10 indivíduos de Anadenanthera colubrina (Vell.) Brenam, Myracrodruon urundeuva (Engl.) Fr. All. e Caesalpinia pyramidalis Tul., os teores de fenóis totais e taninos foram determinados em extratos metanólicos $80 \%$ pelo método de Folin-Ciocalteau, seguido do método da precipitação de proteínas. Adicionalmente, testou-se a hipótese de que a concentração de taninos está diretamente relacionada com a altura e diâmetro das plantas. As espécies estudadas apresentaram expressivos teores de extrativos tânicos, e os resultados não ratificaram a hipótese testada.
\end{abstract}

Palavras-chave: Caatinga, taninos, Anadenanthera colubrina, Myracrodruon urundeuva e Caesalpinia pyramidalis.

\section{TANNIN CONCENTRATION IN THREE SIMPATRIC MEDICINAL PLANTS FROM CAATINGA VEGETATION}

\begin{abstract}
A comparative study of tannin concentration in three medicinal plants from caatinga vegetation (Northeast Brazil) was carried out through colorimetric assays. Bark and leaf samples of 10 individuals of each species were extracted with $80 \%$ methanol. Tannin was determined by Folin-Ciocalteau analysis for total phenolic materials, followed by precipitation with casein. Additionally, it was tested the hypothesis that the tannin concentration is directly related with the height and diameter of the plants. The results show that the studied species contain an expressive amount of tannins.
\end{abstract}

Keywords: Caatinga, tannins, Anadenanthera colubrina, Caesalpinia pyramidalis and Myracrodruon urundeuva.

\section{INTRODUÇÃO}

Taninos são compostos secundários, presentes na maioria das plantas, que podem variar de concentração nos tecidos vegetais, dependendo da idade e tamanho da planta, da parte coletada, da época ou, ainda, do local de coleta (TEIXEIRA et al., 1990; SIMON et al.,1999; LARCHER, 2000). No Brasil, várias espécies são pesquisadas por suas propriedades tanantes; entre as principais estão Stryphnodendron adstringens (Martius) Coville, Dimorphandra mollis Benth., Anadenanthera colubrina (Vell.) Brenam, Acacia mearnssi De Wild, Psidium guajava L. e Myracrodruon urundeuva (Engl.) Fr. All. (TEIXEIRA et al., 1990; BRANDÃO, 1992; RODRIGUES et al., 1992; MAGALHÃES et al., 1997; CALDEIRA et al., 1998; SANTOS et al., 2002).

\footnotetext{
${ }^{1}$ Recebido em $1^{\circ} .04 .2005$ e aceito para publicação em 10.08.2005.

${ }^{2}$ Programa de Pós-Graduação em Botânica da UFRPE.

${ }^{3}$ Aluno do curso de graduação em Licenciatura em Ciências Biológicasda UFPE.

${ }^{4}$ Departamento de Ciências Farmacêuticas, CCS, UFPE.

${ }^{5}$ Departamento de Biologia, UFRPE. * Autor para correspondência, <upa@ufrpe.br>.
} 
Algumas espécies, como M. urundeuva (Engl.) Fr. All. (aroeira-do-sertão) e A. colubrina (Vell.) Brenan (angico), são amplamente distribuídas e exploradas no bioma Caatinga e, em resposta às variações climáticas sazonais, apresentam-se caducifólias durante a estação seca regional (ARAÚJO, 1990). Caesalpinia pyramidalis Tul. também é uma espécie comumente explorada por populações locais, que fazem uso de suas cascas em processos diarréicos e em disenterias (BRAGA, 1960). É uma planta endêmica da caatinga, necessitando, como as outras citadas, de estratégias para conservação e manejo sustentável. A importância dessas espécies reside, principalmente, nas características da madeira (construção, lenha, carvão) e nas suas propriedades medicinais cientificamente comprovadas (antiinflamatória, cicatrizante e antimicrobiana) (MENEZES et al., 1988; CHAVES et al., 1998; VIANA et al., 2003; SALVAT et al., 2004).

De maneira geral, a exploração dessas plantas na caatinga é feita de forma desordenada, pois não existe uma normatização, instituída em lei, para orientar o seu manejo. Na prática, retiram-se da planta extensas áreas de tecido caulinar e que parecem ser independentes da idade e do tamanho do vegetal, bem como da época do ano. No entanto, é necessário que a prática de exploração adotada seja repensada, pois estudos científicos vêm demonstrando que a concentração de taninos nos tecidos vegetais pode ser influenciada por diferentes fatores, entre estes a variação sazonal (SIMON et al., 1999), o local de coleta da planta (TEIXEIRA et al., 1990) e o diâmetro ou tamanho do caule (TEIXEIRA et al., 1990). Considerando que $M$. urundeuva, A. colubrina e C. pyramidalis apresentam grande importância local na caatinga do Nordeste do Brasil (SALES etal., 1989; ALMEIDAeALBUQUERQUE, 2002; ALBUQUERQUE e ANDRADE, 2002ab) e, ainda que a influência do tamanho da planta na quantidade de seus compostos tânicos é desconhecida, justificase um estudo para identificar se a concentração desses compostos mantém relação com as características biométricas do caule. Essas informações permitirão inferir sobre a variação da produção de taninos em relação à ontogenia do indivíduo e disponibilizar informações científicas para orientar o manejo dessas espécies na caatinga, bioma exclusivamente brasileiro, que exibe sérios problemas de conservação (ALBUQUERQUE, 2004).

R. Árvore, Viçosa-MG, v.29, n.6, p.999-1005, 2005
Desse modo, as questões a que se pretendem responder neste estudo são: o teor de taninos varia com a altura e o diâmetro do caule das plantas adultas? O teor de taninos nas cascas e folhas difere entre espécies, ocorrendo numa mesma área? Seria o tamanho das plantas uma boa ferramenta para orientar o manejo da extração de taninos, em plantas adultas na vegetação da caatinga?

\section{MATERIAL E MÉTODOS}

\subsection{Coleta das amostras}

O material utilizado nesta pesquisa constituiuse de amostras de cascas do caule e folhas de três espécies medicinais arbóreas: Myracrodruon urundeuva (Engl.) Fr. All. (aroeira), Anadenanthera colubrina (Vell.) Brenan (angico) e Caesalpinia pyramidalis Tul. (catingueira), coletadas em um fragmento de mata de caatinga, constituído por cerca de 20 ha e pertencente à Estação Experimental da Empresa Pernambucana de Pesquisa Agropecuária (IPA), em Caruaru, Estado de Pernambuco. As espécies foram selecionadas em função do número de indivíduos na área (ALCOFORADO FILHO et al., 2003), bem como pela sua importância na medicina popular (ALBUQUERQUE e ANDRADE, 2002a,b).

As plantas foram selecionadas de parcelas permanentes (ARAÚJO, 1998), que cobrem 1 ha da área. Dez indivíduos de cada espécie foram estudados, e coletaram-se dados como altura e diâmetro à altura do peito (DAP). As cascas (uma amostra por indivíduo) foram coletadas a partir de $1 \mathrm{~m}$ do solo, em uma mesma altura, sendo as folhas maduras retiradas sempre de uma mesma posição, com exceção de $C$. pyramidalis Tul., que não apresentou folhas na época da coleta (agosto de 2003), e cada amostra pesava cerca de cinco gramas.

\subsection{Preparação dos extratos e quantificação dos fenóis e taninos}

A partir das cascas e folhas maduras coletadas, foram preparados extratos em metanol 80\%, com 500 $\mathrm{mg}$ da parte vegetal em $5 \mathrm{~mL}$ do solvente. Foram realizadas cinco extrações sucessivas até o início da fervura, sendo o procedimento realizado em triplicata. As análises dos extratos foram realizadas para determinação de fenóis totais pelo método Folin-Ciocalteau e os taninos totais, pelo método da precipitação da caseína (FOLIN e CIOCALTEAU, 1927; MUELLER-HARVEY, 2001; 
QUEIROZ et al., 2002; SEIGLER et al., 1986; READEL et al., 2001). Alterações no método foram inseridas visando à adequação aos teores de compostos fenólicos e taninos encontrados em cada espécie. O método Folin-Ciocalteau consistiu em adicionar $0,25 \mathrm{~mL}$ do extrato em um balão volumétrico de $100 \mathrm{~mL}$ contendo $75 \mathrm{~mL}$ de água, adicionando-se $5 \mathrm{~mL}$ do reagente Folin-Ciocalteau (solução aquosa 10\%), $10 \mathrm{~mL}$ de solução de carbonato de sódio $(7,5 \%)$ e volume completado com água destilada. Essa solução foi agitada adequadamente e depois ficou em repouso por 30 minutos. Após esse período, a absorbância foi lida a $760 \mathrm{~nm}$. O mesmo procedimento foi adotado para as soluções-padrão de ácido tânico, nas seguintes concentrações: 0,$1 ; 0,5 ; 1,0 ; 2,5$; e 3,75 $\mu \mathrm{g} \cdot \mathrm{mL}^{-1}$ (Figura 1).

Os taninos foram determinados pelo método da precipitação pela caseína, que consistiu em adicionar a um erlenmeyer de $50 \mathrm{~mL} 1 \mathrm{~g}$ de caseína em pó e alíquotas de $6 \mathrm{~mL}$ do extrato diluído em $12 \mathrm{~mL}$ de água, que foram mantidos sob agitação constante por três horas na temperatura ambiente $\left(25^{\circ} \mathrm{C}\right)$. Depois, as amostras foram filtradas em papel-filtro Whataman de $9 \mathrm{~cm}$ e o volume do filtrado resultante, completado para 25 $\mathrm{mL}$. Alíquotas variando de 8 a $12 \mathrm{~mL}$, dependendo da espécie, foram removidas dessa solução e os fenóis residuais, determinados pelo método Folin-Ciocalteau. A quantidade de taninos correspondeu à diferença entre o valor encontrado nessa leitura e o obtido na determinação de fenóis totais. Estes fenóis e taninos foram expressos em $\mathrm{mg}$ de matéria seca.

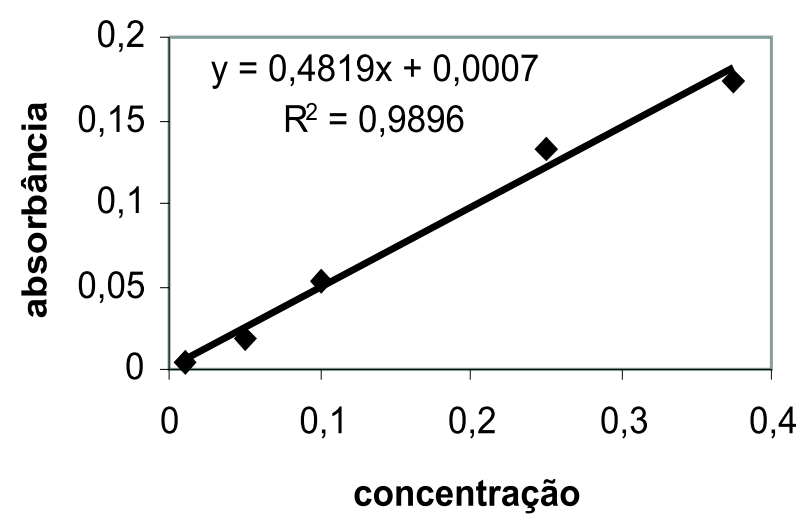

Figura 1 - Curva de calibração da concentração de ácido tânico em mg.mL $\mathrm{mL}^{-1}$ pela absorbância. Em evidência, encontram-se a equação da reta e o erro do ajuste.

Figure 1 - Standard curve of solutions of tannic acid ( $\left.\mathrm{m} g . m L^{-1}\right)$ by absorbance.

\subsection{Análise dos dados}

Foi utilizado o teste Kolmogorov-Smirnov para verificar a normalidade dos dados (ZAR, 1996). Para avaliar a correlação entre as alturas, diâmetros e teores de taninos nas três espécies, usou-se o coeficiente de Correlação de Pearson e para evidenciar diferenças nos teores de taninos nas três espécies, o teste t. Todas as análises foram realizadas empregando-se o software BioEstat 2.0 (AYRES et al., 2000).

\section{RESULTADOS E DISCUSSÃO}

\subsection{Teor de fenóis totais e taninos nas espécies estudadas}

Os valores médios das quantidades de fenóis totais e taninos nas cascas e folhas das espécies estudadas estão apresentados na Tabela 1 .

A quantidade de taninos variou intraespecificamente, em relação às cascas e folhas, e entre as espécies estudadas. Variações intra-específicas não são raras, como já foi documentado em diferentes populações de Stryphnodendron adstringens (Martius) Coville (TEIXEIRA et al., 1990). As quantidades variaram nas cascas de A. colubrina (Vell.) Brenan de 16,04 a $55,34 \mathrm{mg}$ (3,21 a 11,07\%), variação maior que a encontrada em M. urundeuva (Engl.) Fr. All, 35,20 a 51,90 mg (7,04 a $10,38 \%$ ). As folhas de A. colubrina (Vell.) Brenan apresentaram variação de 17,93 a 41,46 mg (3,59 a 8,29\%), e as de $M$. urundeuva (Engl.) Fr. All variaram de 13,50 a 50,87 mg (2,18 a 9,56\%). Nas cascas de C. pyramidalis Tul., a variação foi de 6,90 a 38,57mg $(1,38$ a 7,71\%).

Não houve diferenças entre as quantidades de fenóis totais (Tabela 1) nas cascas entre $M$. urundeuva e $A$. colubrina. No entanto, M. urundeuva em média produz maior quantidade de extrativos fenólicos do que $C$. pyramidalis. Também não houve diferenças significativas entre cascas e folhas das espécies testadas (Tabela 1).

Comparando a quantidade média de taninos (Tabela 1) entre as cascas de M. urundeuva e A. colubrina, verificou-se que a média da última é ligeiramente menor, contudo essa diferença não foi significativa. Por sua vez, A. colubrina e C. pyramidalis apresentaram diferenças significativas entre as quantidades médias de taninos nas cascas. As médias dos teores de taninos nas cascas em $M$. urundeuva e $C$. pyramidalis também foram estatisticamente diferentes, com a ressalva de que a última espécie exibiu menores quantidades de compostos tânicos.

R. Árvore, Viçosa-MG, v.29, n.6, p.999-1005, 2005 
Tabela 1 - Quantidades médias de fenóis e taninos totais seguidos de desvio-padrão em Myracrodruon urundeuva (Engl.) Fr. All., Anadenanthera colubrina (Vell.) Brenan e Caesalpinia pyramidalis Tul., coletados em uma área de caatinga no município de Caruaru, PE. Os valores entre parênteses representam a faixa de variação dos teores obtidos nos 10 indivíduos

Table 1 - Concentration of total phenolics and tannins (mean \pm standart deviation) in Myracrodruon urundeuva (Engl.) Fr. All., Anadenanthera colubrina (Vell.) Brenan and Caesalpinia pyramidalis Tul. The values in parentheses represent the range of variation

\begin{tabular}{lcccc}
\hline Espécies & \multicolumn{2}{c}{ Fenóis Totais $(\mathrm{mg})$} & \multicolumn{2}{c}{ Taninos $(\mathrm{mg})$} \\
\cline { 2 - 5 } & Casca & Folha & Casca & Folha \\
\hline Anadenanthera colubrina & $41,39 \pm 14,51$ & $33,44 \pm 07,89$ & $37,90 \pm 13,16$ & $27,89 \pm 07,24$ \\
(Vell.) Brenan & $(03,45-12,24 \%) \mathrm{AaB}$ & $(04,67-09,82 \%)$ a & $(03,21-11,07 \%)$ Aa & $(03,59-08,29 \%)$ Aa \\
Myracrodruon urundeuva & $46,44 \pm 07,05$ & $36,85 \pm 12,32$ & $40,93 \pm 05,37$ & $33,57 \pm 11,59$ \\
(Engl.) Fr. All. & $(07,49-12,19 \%) \mathrm{AaC}$ & $(02,97-10,89 \%)$ a & $(07,04-10,38 \%) \mathrm{Aa}$ & $(02,18-9,56 \%) \mathrm{Aa}$ \\
Caesalpinia & $29,60 \pm 12,69$ & $\mathrm{ND}$ & $24,72 \pm 11,53$ & $\mathrm{ND}$ \\
pyramidalis Tul. & $(1,83-8,85 \%) \mathrm{BD}$ & & $(1,38-7,71 \%) \mathrm{B}$ & \\
\hline
\end{tabular}

Médias seguidas da mesma letra minúscula (linha) e maiúscula (coluna) não diferem entre si, a 5\% de probabilidade. ND = não foi determinado: e não continha folhas na época da coleta.

Não foram encontradas diferenças significativas entre as médias de taninos das cascas e folhas e entre as espécies que as continham na época da coleta. No geral, a quantidade de taninos das cascas foi ligeiramente maior, porém essa diferença não foi significativa (Tabela 1), apesar da forte tradição em torno do uso medicinal das cascas dessas espécies, o que parecia apontar para diferenças expressivas. Provavelmente, isso ocorre porque as cascas mantêmse como recurso disponível para as pessoas durante todo o ano.

Tanto $M$. urundeuva quanto $A$. colubrina contêm em suas cascas maior quantidade de compostos tânicos do que C. pyramidalis, embora estas duas últimas pertençam ao mesmo grupo (Leguminosae Lato senso). As leguminosas são reportadas como uma valorosa família, no que diz respeito à produção de taninos. Espécies de Acacia, por exemplo, são demandadas em várias regiões do mundo pela quantidade de taninos em seus tecidos e podem variar de 1 a $23 \%$, dependendo do solvente utilizado e da parte da planta (SEIGLER et al., 1986). Apesar de as espécies aqui estudadas demonstrarem porcentuais tânicos menores que os de outras espécies, consideradas referências no que tange à produção desses compostos, como $A$. mearnsii $\mathrm{e}$ Schinopsis balansae Engl., elas são altamente exploradas como recursos terapêuticos, por populações locais e até mesmo por pequenas indústrias e laboratórios.

As anacardiáceas são reconhecidas pela ampla distribuição de fenóis (AGUILAR-ORTIGOZA, 2003). Por exemplo, a madeira seca de S. balansae Engl., popularmente conhecido como quebracho, contém $25 \%$ de taninos condensados (SEIGLER et al., 1986). No Brasil, o mais popular representante da família é a aroeira, por possuir altos valores de compostos tânicos em suas cascas. Queiroz et al. (2002) encontraram elevadas quantidades de compostos fenólicos na madeira de M. urundeuva (Engl.) Fr. All., cerca de 20,2\% (equivalente em ácido gálico) dos extratos brutos metanólicos, e Morais et al. (1998), por sua vez, registraram grande quantidade de extrativos em M. urundeuva (Engl.) Fr. All (=Astronium urundeuva), sendo estes constituídos principalmente de proantocianidinas.

A comparação dos resultados obtidos com os da literatura, de certa forma, encontra-se limitada pelo fato do uso de técnicas analíticas distintas ou, ainda, da coleta de outros tecidos e não apenas cascas e folhas, como realizado no presente trabalho.

\section{2. Teor de taninos $X$ altura e diâmetro}

Verificaram-se diferenças intra-específicas expressivas tanto nas alturas quanto nas classes diamétricas. Em $A$. colubrina houve variação nas alturas dos indivíduos de 5 a 13 m e diâmetro de 6,36 a 15,92 $\mathrm{cm}$. Os espécimes de M. urundeuva (Engl.) Fr. All, por sua vez, variaram de 5,5 a 12,5 m nas alturas e, diâmetro, de 6,69 a $12,57 \mathrm{~cm}$. A espécie $C$. pyramidalis apresentou alturas entre 4,5 e 10 m e diâmetro de 6,37 a $10,51 \mathrm{~cm}$. Na Figura 2 estão correlacionados os teores de taninos com as variáveis analisadas, considerando-se cada espécie isoladamente. Foi observada correlação positiva, mas não significante em A. colubrina, M. urundeuva e C. pyramidalis (Figura 2). 

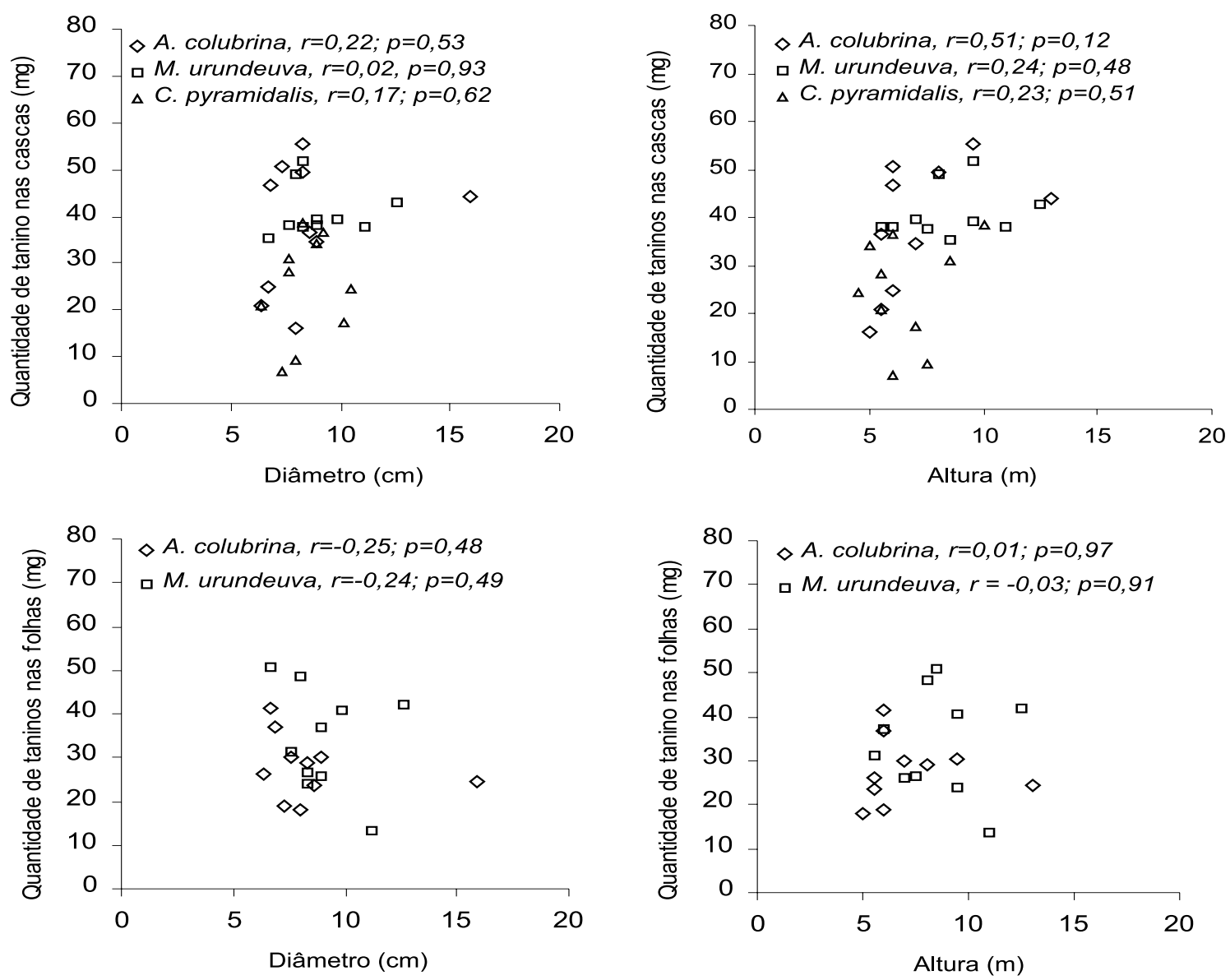

Figura 2 - Relação entre a quantidade de tanino em cascas (A, B) e folhas (C, D), em $500 \mathrm{mg}$ da amostra, com características biométricas de plantas adultas de três espécies medicinais da caatinga: Myracrodruon urundeuva (Engl.) Fr. All., Anadenanthera colubrina (Vell.) Brenan e Caesalpinia pyramidalis Tul.

Figure 2 - Concentration of total tannins in bark $(A, B)$ and leaves $(C, D)$ in relation to biometric characteristics of three medicinal plants from caatinga vegetation: Myracrodruon urundeuva (Engl.) Fr. All., Anadenanthera colubrina (Vell.) Brenan and Caesalpinia pyramidalis Tul.

A concentração de taninos nas espécies estudadas, portanto, não se encontra associada com as características biométricas analisadas, à semelhança do observado por Teixeira et al. (1990) em S. adstringens (Mart.) Coville com relação a classes diamétricas e em diferentes pontos de coleta ao longo do fuste em $A$. mearnssi De Wild. (CALDEIRA et al., 1998). Contraditoriamente, Silva e Frizzo (1985) encontraram variação significativa, ao longo da altura do caule, nos teores de taninos em A. mearnssi De Wild.

A comparação dos dados aqui descritos com os citados é limitada, uma vez que se analisou a altura total de cada indivíduo.

\section{CONCLUSÕES}

- A concentração de taninos não foi afetada pela altura total e pelo diâmetro nas espécies estudadas.

- As cascas do caule de A. colubrina e M urundeuva concentraram mais compostos tânicos que as de $C$. pyramidalis.

- Com base nos parâmetros analisados, as características biométricas não permitem subsidiar propostas de manejo, salvo o fato de que se deve orientar a extração para indivíduos de grande porte, para que suportem a pressão extrativista das cascas.

- Considerando que não foram observadas

R. Árvore, Viçosa-MG, v.29, n.6, p.999-1005, 2005 
diferenças significativas entre os teores presentes em cascas e folhas, embora nas primeiras sejam ligeiramente maiores, propõe-se um sistema de manejo e extração que promova, em determinadas épocas, a intercalação dos recursos, visando reduzir a pressão sobre as cascas.

- É imprescindível a realização de estudos futuros que permitam a elucidação da influência de fatores extrínsecos e intrínsecos à planta, os quais podem afetar a produção de compostos tânicos e respaldar programas de manejo sustentável.

\section{AGRADECIMENTOS}

À Estação Experimental da Empresa Pernambucana de Pesquisa Agropecuária (IPA), em Caruaru, Estado de Pernambuco, pelo apoio logístico; e a Ruth R. Strattmann, técnica do Núcleo de Controle de Qualidade e Medicamentos Correlatos do Departamento de Ciências Farmacêuticas da Universidade Federal de Pernambuco, pela valorosa contribuição em todo o procedimento experimental.

\section{REFERÊNCIAS BIBLIOGRÁFICAS}

AGUILAR-ORTIGOZA, C. J.; SOSA, V.; AGUILARORTIGOZA, M. Toxic phenols in various Anacardiaceae species. Economic Botany, v.57, n. 3, p 354 - 364. 2003.

ALBUQUERQUE, U. P. Etnobotânica Aplicada para a Conservação da Biodiversidade. In: ALBUQUERQUE, U. P.; LUCENA, R. F. P. Métodos e técnicas na pesquisa etnobotânica. Recife: NUPEEA/Livro Rápido, 2004.

ALBUQUERQUE, U. P; ANDRADE, L. H. C. Conhecimento botânico tradicional e conservação em uma área de caatinga no Estado de Pernambuco, Nordeste do Brasil. Acta Botanica Brasilica, v. 16, n. 3. p. 273-285, 2002a.

ALBUQUERQUE, U. P.; ANDRADE, L. H. C. Uso de recursos vegetais da caatinga: o caso do agreste do Estado de Pernambuco (Nordeste do Brasil).

Interciência, v. 27, n. 7. p. 336 - 345, 2002b.

ALCOFORADO-FILHO, F. G.; SAMPAIO, E. V. S. B.; RODAL, M. J. N. Florística e fitossociologia de um remanescente de vegetação caducifólia espinhosa arbórea em Caruaru, Pernambuco. Acta Botanica Brasilica, v.17, n.2, p.287-303, 2003.

R. Árvore, Viçosa-MG, v.29, n.6, p.999-1005, 2005
ALMEIDA, C. F. C. B. R. \& ALBUQUERUE, U. P. Uso e conservação de plantas e animais medicinais no Estado de Pernambuco (Nordeste do Brasil): Um estudo de caso. Interciência, v. 27 , n. 6 , p. $276-285,2002$.

\section{ARAujo, E. L. Composição floristica e estrutura da vegetação em três áreas de caatinga de Pernambuco. 1990. $176 \mathrm{f}$. Dissertação (Mestrado em Botânica) - Universidade Federal Rural de Pernambuco, Recife, 1990.}

ARAúJo, E. L. Aspectos da dinâmica populacional de duas espécies em floresta tropical seca (caatinga), Nordeste do Brasil. 1998. 95f. Tese (Doutorado em Biologia Vegetal) - Universidade Estadual de Campinas, Campinas, 1998.

AYRES, M. et al. Bioestat 2.0: aplicações estatísticas nas áreas das ciências biológicas e médicas. Brasília: Sociedade Civil Mamirauá, CNPq, 2000. 260p.

BRAGA, R. Plantas do Nordeste, especialmente do Ceará. 4.ed. Recife: Universidade Federal do Rio Grande do Norte, $1960.540 \mathrm{p}$.

BRANDÃO, M. Plantas produtoras de taninos nos cerrados mineiros. Informe Agropecuário, v. 16, n. 173, p 33 - 35, 1992.

CALDEIRA, M. V. W. et al. Quantificação de taninos em três povoamentos de Acacia mearnsii De Wild. Boletim de Pesquisas Florestais, n. 37, p. 81 - 88, 1998.

CHAVES, M. C. et al. Experimental evaluation of Myracrodruon urundeuva bark extract for antidiarrhoeal activity. Phytotherapy Research, v. 12, p. $549-552,1998$.

FOLIN, O.; CIOCALTEAU, V. On tyrosine and tryptophane determination in proteins. Journal of Biology and Chemistry , v.73, p. 424-427, 1927.

LARCHER, W. Ecofisiologia vegetal. São Paulo: RiMa, 2000. 531p. 
MAGALHÃES, P. C.; RODRIGUES, W. A.; DURÃES, F. O. M. Tanino no Grão de Sorgo - Bases Fisiológicas e Métodos de Determinação. Brasília: 27, Embrapa, 1997. (Circular Técnica, 27).

MENEZES, A. M. S.; RAO, V. S. Effect of Astronium urundeuva (aroeira) on gastrointestinal transit in mice. Brazilian Journal of Medical and Biological Research, v. 21, p. $531-533,1988$.

MORAIS, S. A. L.; NASCIMENTO, E. A.; QUEIROZ, C. R. A. A. Studies on polyphenols and lignin of Astronium urundeuva wood. Journal of Brazilian Chemical Society, v. 10, n. 6, p. 447 - 452, 1998.

MUELLER-HARVEY, I. Analysis of hydrolysable tannins. Animal Feed Science and Technology, v. 91, p. 3 - 20, 2001.

QUEIROZ, C. R. A. A.; MORAIS, S. A. L.; NASCIMENTO, E. A. Caracterização dos taninos da aroeira-preta (Myracrodruon urundeuva).

Revista Árvore, v. 26, n. 4, p. 485 - 492, 2002.

READEL, K. et al. Tannins from mimosoid legumes of Texas and México. Economic Botany, v.55, n. 2, p. $212-222,2001$.

RODRIGUES, W. A. et al. Variabilidade para o teor de tanino em sorgo (Sorghum bicolor L.) e sua associação com a resistência a pássaros.

Ciência Prática, v. 16, p. 74 - 77, 1992.

SALES, M. F.; LIMA, M. J. A. Formas de uso da flora da caatinga pelo assentamento da microrregião de Soledade (PB). In: REUNIÃO NORDESTINA DE BOTÂNICA, 8., 1989, Recife. Anais... Recife: Sociedade Botânica do Brasil, Seccional de Pernambuco, Brasil, 1989. p. 165-184.
SALVAT, A. et al. Antimicrobial activity in methanolic extracts of several plant species from northern Argentina Phytomedicine, v. 11, p. $230-234,2004$

SANTOS, S. C. et al. Tannin composition of barbatimão species. Fitoterapia, v. 73, p. 292-299, 2002.

SEIGLER, D. S. et al. Tannins from Four Common Acacia Species of Texas and Northeastern Mexico. Journal Science Food Agriculture, v. 29, p. 778 - 794, 1986.

SILVA, M. C.; FRIZZO, S. M. Determinação de taninos na casca de Acacia mearnsii De Wild., em diferentes alturas do tronco. Ciência e Natura, n. 7, p. $57-61,1985$.

SIMÓN, B. F.; CADAHIA, E.; CONDE, E. Evolution of phenolic compounds of spanish oak wood during natural seasoning. First results.

Journal of Agricultural Food Chemistry, 47, p. 1687 - 1694, 1999.

TEIXEIRA, M. L.; SOARES, A. R.; SCOLFORO, J. R. S. Variação do teor de tanino da casca de barbatimão [Stryphnodendron adstringens (Mart.) Coville] em 10 locais de Minas Gerais. Ciência Prática, v. 14, n. 2, p. 229 - 232, 1990.

VIANA, G. S. B.; BANDEIRA, M. A. M.; MATOS, F.JA. Analgesic and antiinflammatory effects of chalcones isolated from Myracrodruon urundeuva Allemao. Phytomedicine, v. 10, p.189 - 195, 2003.

ZAR, J. H. Bioestatistical analysis. London: Prentice-Hall, 1996. 662p.

R. Árvore, Viçosa-MG, v.29, n.6, p.999-1005, 2005 